Artigo

\title{
Células de Circulação Meridional Durante os Eventos Extremos de Gelo Marinho Antártico
}

\author{
Camila Bertoletti Carpenedo, Tércio Ambrizzi \\ Departamento de Ciências Atmosféricas, Instituto de Astronomia, Geofisica e Ciências \\ Atmosféricas, Universidade de São Paulo, São Paulo, SP, Brasil
}

Recebido: 29/11/2015 - Aceito: 9/5/2016

\begin{abstract}
Resumo
Como a borda do gelo marinho antártico está localizada em uma região muito sensível, sob a Frente Polar Antártica, existe um grande potencial da variabilidade do gelo marinho afetar a circulação atmosférica. Assim, o objetivo deste estudo foi investigar as possíveis relações entre os eventos extremos de gelo marinho antártico e as células de circulação meridional no Pacífico Sudeste, região onde há intensa variabilidade em várias escalas de tempo. Os resultados mostram que quando há eventos extremos de expansão de gelo marinho no setor do mar de Ross, existe um resfriamento da TSM, que resulta em uma atmosfera adjacente fria, aumentando os gradientes térmicos entre a borda do gelo marinho e a região de mar aberto. Os gradientes de pressão são fortalecidos, fortalecendo o cinturão circumpolar de baixas pressões e o jato polar. Assim, existe um fortalecimento do ramo ascendente da célula de Ferrel sobre o Oceano Austral, enquanto há enfraquecimento nas latitudes médias, por conservação de massa. Observamos o padrão oposto em eventos extremos de retração de gelo marinho no setor do mar de Ross e expansão no setor do mar de Weddell.
\end{abstract}

Palavras-chave: células de circulação meridional, gelo marinho, variabilidade interanual.

\section{Cells of Meridional Circulation During the Extreme Events of Antarctic Sea Ice}

\begin{abstract}
Because the Antarctic sea ice edge is located in a region quite sensible, under the Antarctic Polar Front, there is a great potential of sea ice variability to affect the atmospheric circulation. The objective of this study was to investigate possible relationships between the extreme events of Antarctic sea ice and the cells of meridional circulation over the Southeastern Pacific, where there is intense climate variability on various time scales. The results show that when there are extreme events of sea ice expansion in the Ross Sea sector there is cooling of the SST, which results in the surrounding atmosphere cools, increasing the thermal gradient between the edge of sea ice and the open water region. The southern pressure gradients are strengthened, which strengthens the circumpolar low pressure belt and the polar jet. So there is a strengthening of the ascending branch of the Ferrel cell over the Southern Ocean while there is a weakening in midlatitudes via conservation of mass. We observe the opposite pattern in extreme events of sea ice decrease in the Ross Sea sector and expansion in the Weddell Sea sector.
\end{abstract}

Keywords: cells of meridional circulation, sea ice, interannual variability.

\section{Introdução}

Gelo marinho é qualquer forma de gelo formado pelo congelamento da água do mar (Simões, 2004). O gelo marinho possui um papel importante no sistema climático global. Este papel é em grande parte atribuído ao fato do gelo marinho alterar o albedo da superfície oceânica, afetando a quantidade de radiação solar absorvida. Assim, o albedo típico do oceano de cerca de $10-15 \%$ passa para valores de até $90 \%$ quando coberto por gelo marinho (King e Turner, 1997; Wadhams, 2000; Thomas e Dieckmann, 2010). O gelo marinho também possui baixa condutividade térmica, inibindo as trocas de calor, massa e momento entre oceano-atmosfera (King e Turner, 1997). O derretimento e congelamento do gelo marinho influencia a estabilidade do

Autor de correspondência: Camila Bertoletti Carpenedo, camila.carpenedo@iag.usp.br. 
oceano superior devido às variações de salinidade, o que afeta diretamente o processo de formação de massas de água e, desta forma, possui potencial de alterar a circulação termohalina global (King e Turner, 1997; Wadhams, 2000). O gelo marinho também influencia a formação de massas de ar nas altas latitudes. No verão austral, devido à máxima retração sazonal do gelo marinho antártico, a massa de ar formada sobre o Oceano Austral, entre a Convergência Subtropical e a borda do gelo marinho, é chamada de marítima polar (Taljaard, 1972). Contudo, no inverno austral o limite sul da região de origem da massa de ar marítima polar está ao norte da borda do gelo marinho, de forma que sobre o Oceano Austral coberto por gelo marinho é formada uma massa de ar mais fria, a marítima antártica (Taljaard, 1972).

Estudos realizados com modelos de circulação geral (e.g. Simmonds e Budd, 1991; Simmonds e Wu, 1993; Menéndez et al., 1999a, b; Raphael et al., 2010) mostram que uma redução ou remoção na cobertura de gelo marinho antártico resulta em diminuição nos gradientes meridionais de temperatura e pressão, enfraquecendo o cinturão circumpolar de baixas pressões. Essa configuração teria um impacto significativo na propagação de sistemas frontais, afetando a precipitação nas latitudes médias do Hemisfério Sul (Simmonds e Budd, 1991; Simmonds e Wu, 1993; Menéndez et al., 1999b). Raphael et al. (2010) utilizam um modelo de circulação geral acoplado, em que o submodelo de gelo marinho é substituído pela climatologia de extremos de concentração de gelo marinho antártico observada para o verão austral (janeiro, fevereiro e março). Os autores mostram que em condições de mínima (máxima) cobertura de gelo marinho a célula Polar expande (contrai), de forma que a célula de Ferrel é deslocada para norte (sul).

Desta forma, nossa hipótese é que como a borda do gelo marinho antártico está localizada em uma região muito sensível, sob a Frente Polar Antártica, existe um grande potencial da variabilidade do gelo marinho afetar a circulação atmosférica, da superfície até os níveis médios da troposfera (Raphael et al., 2010). Além disso, o Pacífico Sudeste é uma região de intensa variabilidade climática em várias escalas de tempo, sendo a localização da máxima amplitude do modo Pacífico-América do Sul (Pacific-South American - PSA), padrão mais diretamente relacionado à variabilidade do fenômeno tropical El Niño-Oscilação Sul (ENOS), influenciando o gelo marinho antártico principalmente na escala de tempo interanual (Yuan e Li, 2008), bem como é a área de maior frequência de bloqueios atmosféricos do Hemisfério Sul (Renwick, 1998; Mo e Paegle, 2001; Oliveira et al., 2013). Assim, o objetivo deste estudo é investigar as possíveis relações entre os eventos extremos de cobertura de gelo marinho nos diferentes setores do Hemisfério Sul e as células de circulação meridional no Pacífico Sudeste.

\section{Material e Métodos}

Dados de extensão de gelo marinho são disponibilizados pelo National Snow and Ice Data Center desde 01/11/1978. Este dado é uma estimativa a partir da temperatura de brilho dos sensores SMMR (Scanning Multichannel Microwave Radiometer) e SSM/I (Special Sensor Microwave/Imager). A temperatura de brilho é convertida para concentração de gelo marinho através do algoritmo NASA Team (Cavalieri et al., 1999). A concentração de gelo marinho representa uma estimativa média da cobertura de gelo marinho, devendo ser superior a $15 \%$ para cada pixel, com espaçamento horizontal de $25 \mathrm{~km}$ x $25 \mathrm{~km}$. A partir deste dado é possível calcular a extensão de gelo marinho, que é definida como a área total coberta por gelo marinho com concentração média superior a $15 \%$. Médias de extensão de gelo marinho são disponibilizadas para cada setor do Hemisfério Sul (Fig. 1): mar de Weddell, mares de Bellingshausen-Amundsen, mar de Ross, Oceano Pacífico Oeste e Oceano Índico.

As anomalias diárias de extensão de gelo marinho para cada setor foram determinadas pela remoção do ciclo anual e semianual, calculados a partir do primeiro e segundo harmônico ajustados ao ciclo anual médio de extensão de gelo marinho nos diferentes setores. Estas anomalias foram dessazonalizadas pela remoção da tendência linear e posteriormente foram filtradas com o filtro transformada rápida de Fourier, no período superior a 365 dias, gerando séries de anomalias interanuais. Determinamos os extremos de anomalias interanuais de extensão de gelo marinho baseados nos quartis da distribuição sazonal. O foco do presente estudo é o inverno austral (julho, agosto e setem-

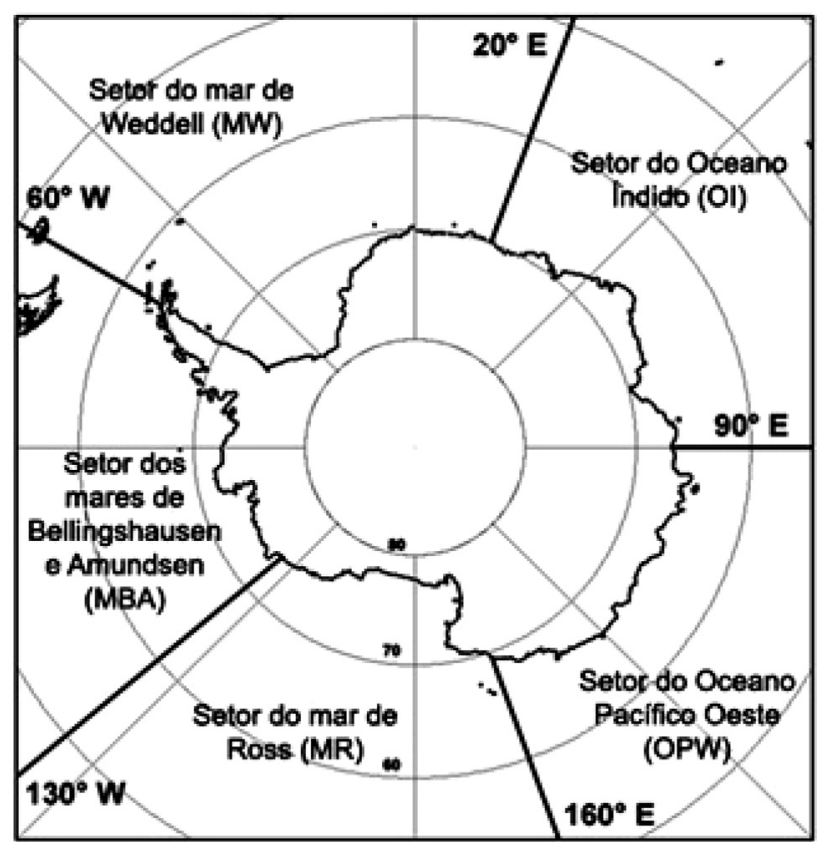

Figura 1 - Setores do Hemisfério Sul (modificado de Cavalieri e Parkinson, 2008). 
bro), pois é o período de máxima extensão de gelo marinho antártico (Cavalieri et al., 1996; Zwally et al., 2002). Assim, definimos os extremos de retração (expansão) de anomalias interanuais de gelo marinho como abaixo (acima) do quartil de $25 \%$ (75\%) da distribuição sazonal. Eventos extremos interanuais de gelo marinho são definidos como os extremos interanuais com persistência de pelo menos 45 dias consecutivos (Tabela 1).

Utilizamos os campos atmosféricos e de superfície oriundos das reanálises do ERA-Interim (ECMWF Data Server). ERA-Interim é a reanálise atmosférica global mais recente produzida pelo ECMWF, desenvolvida para corrigir alguns erros da reanálise ERA-40, particularmente em relação à representação do ciclo hidrológico (Uppala et al., 2008), à qualidade da circulação estratosférica e à contaminação de sinais climáticos por mudanças no sistema de observação (Dee, 2005; Bengtsson et al., 2007). No ERA-Interim a assimilação de dados produz parâmetros em superfície e em 37 níveis de pressão, sendo o nível superior em $0,1 \mathrm{hPa}$ (Berrisford et al., 2009), com espaçamento horizontal de $1,5^{\circ}$ de latitude/longitude. As configurações e o desempenho do sistema de assimilação de dados podem ser vistos com maior detalhe em Simmons et al. (2007), Simmons et al. (2007), Uppala et al. (2008) e Dee et al. (2011).

Por fim, fizemos composições dos campos atmosféricos e de superfície durante os eventos extremos de retração e expansão de gelo marinho nos diferentes setores do Hemisfério Sul. Com a finalidade de investigar as células de circulação meridional, analisamos as composições de velocidade vertical (omega) de 1000 a $100 \mathrm{hPa}$ separadamente para o setor do Pacífico Sudeste $\left(120^{\circ} \mathrm{W}\right.$ a $\left.80^{\circ} \mathrm{W}\right)$. Calculamos a significância estatística através do teste $t$-Student, ao nível de $10 \%$.

\section{Resultados e Discussão}

Durante os eventos extremos de retração (expansão) de gelo marinho no setor do mar de Weddell há um aquecimento (resfriamento) da temperatura da superfície do mar (TSM) neste setor e no Atlântico Sul [Fig. 2a (2b)], o que resulta em aumento (diminuição) da temperatura do ar próximo à superfície [Fig. 2c (2d)]. Por outro lado, no Pacífico Sul existe um resfriamento (aquecimento) da TSM, o que resulta em redução (aumento) da temperatura do ar. A configuração anômala durante os eventos extremos de expansão de gelo marinho reduz os gradientes meridionais de temperatura e pressão em superfície no Pacífico Sul, resultando em aumento da pressão ao nível médio do mar (PNMM) ao sul de $55^{\circ} \mathrm{S}$ (Fig. 2f) e em enfraquecimento do jato polar em torno de $60^{\circ} \mathrm{S}$ (Fig. 2h). Assim, há um consequente reforço do ramo descendente da célula Polar ao sul de $70^{\circ} \mathrm{S}$ e enfraquecimento do ramo ascendente da célula de Ferrel entre $70^{\circ}$ e $50^{\circ} \mathrm{S}$ (Fig. 2j), o que indica um enfraquecimento do cinturão circumpolar de baixas pressões. Por conservação de massa, nas latitudes tropicais do Pacífico Sul há uma redução da PNMM, o que indica um enfraquecimento da Alta Subtropical do Pacífico Sul. O ramo ascendente da célula de Hadley enfraquece entre $10^{\circ}$ e $20^{\circ} \mathrm{N}$, enquanto o ramo descendente intensifica na região equatorial.

Nos eventos extremos de retração (expansão) de gelo marinho no setor dos mares de Bellingshausen-Amundsen há um aquecimento (resfriamento) da TSM neste setor e no Pacífico Sul [Fig. 3a (3b)], o que resulta em aumento (diminuição) da temperatura do ar próximo à superfície [Fig. 3c (3d)]. As anomalias quentes (frias) de TSM e temperatura do ar são menos (mais) abrangentes espacialmente, compreendendo o setor dos mares de Bellingshausen-Amundsen em torno de $60^{\circ} \mathrm{S}$ (todo o Pacífico Sul centro-leste). Assim, durante os eventos extremos de expansão há um reforço dos gradientes meridionais de tem-

Tabela 1 - Anos com eventos extremos de retração e expansão de gelo marinho nos setores do mar de Weddell (MW), mares de BellingshausenAmundsen (MBA), mar de Ross (MR), Oceano Pacífico Oeste (OPW) e Oceano Índico (OI) no inverno austral (1979-2013).

\begin{tabular}{|c|c|c|c|c|c|c|c|c|c|}
\hline \multicolumn{2}{|c|}{ MW } & \multicolumn{2}{|c|}{ MBA } & \multicolumn{2}{|c|}{ MR } & \multicolumn{2}{|c|}{ OPW } & \multicolumn{2}{|c|}{$\mathrm{OI}$} \\
\hline Retração & Expansão & Retração & Expansão & Retração & Expansão & Retração & Expansão & Retração & Expansão \\
\hline 1982 & 1979 & 1980 & 1979 & 1980 & 1984 & 1980 & 1982 & 1986 & 1982 \\
\hline 1983 & 1980 & 1981 & 1986 & 1986 & 1985 & 1986 & 1983 & 1987 & 1985 \\
\hline 1986 & 1981 & 1983 & 1990 & 1992 & 1988 & 1987 & 1990 & 1991 & 1989 \\
\hline 1989 & 1987 & 1988 & 2004 & 1993 & 1989 & 1989 & 1993 & 1996 & 1993 \\
\hline 1990 & 1991 & 1989 & 2009 & 1995 & 1990 & 1991 & 1999 & 1997 & 1999 \\
\hline 1999 & 1992 & 1992 & 2010 & 2002 & 1996 & 2002 & 2003 & 2002 & 2004 \\
\hline 2011 & 1995 & 1998 & 2011 & 2003 & 1998 & 2004 & 2005 & 2007 & 2006 \\
\hline \multirow[t]{3}{*}{2013} & 2003 & 2006 & 2012 & 2004 & 1999 & 2009 & 2011 & 2011 & 2010 \\
\hline & 2004 & 2007 & 2013 & 2011 & 2000 & 2010 & 2012 & & 2013 \\
\hline & & & & 2012 & 2007 & & 2013 & & \\
\hline
\end{tabular}



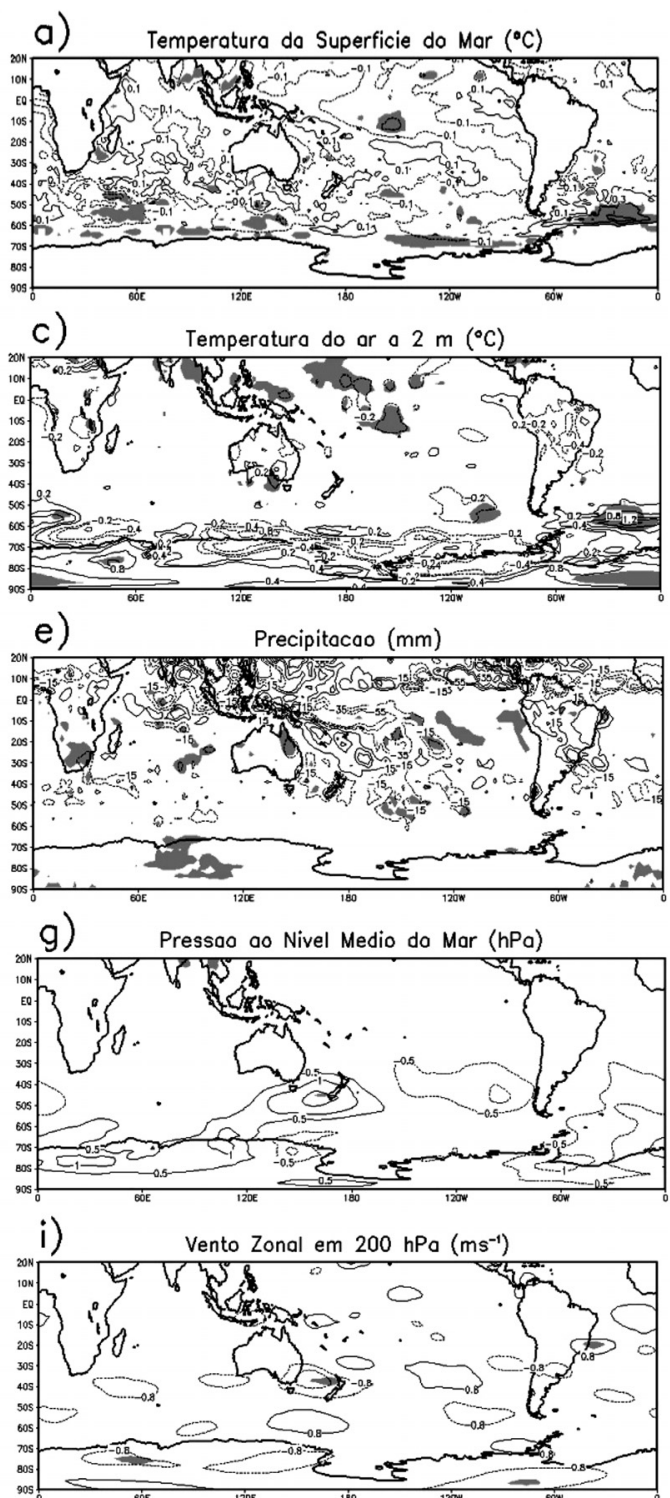

k) Omega $\left(10^{-2} \mathrm{~Pa} \mathrm{~s}^{-1}\right)$
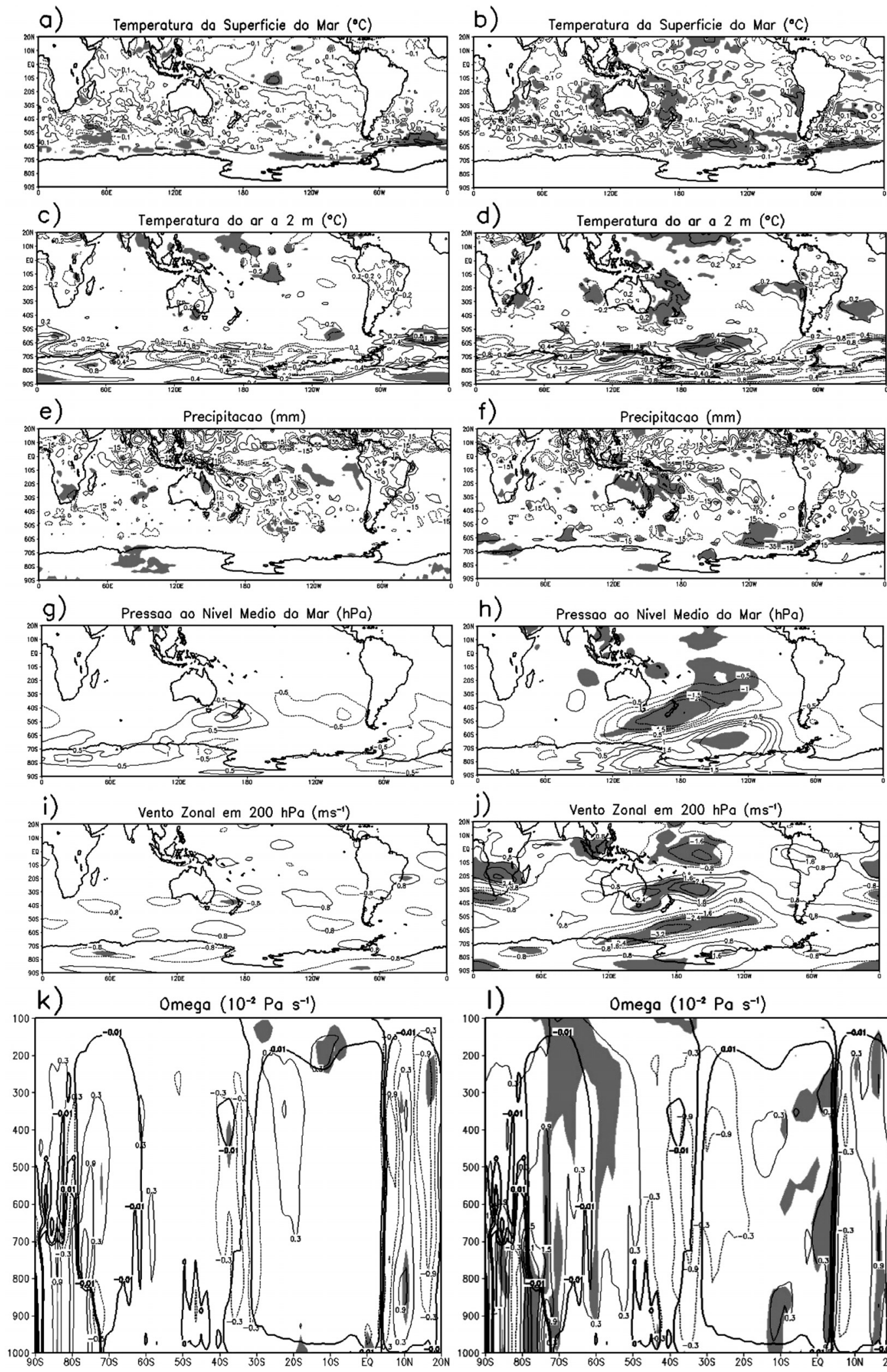

d)
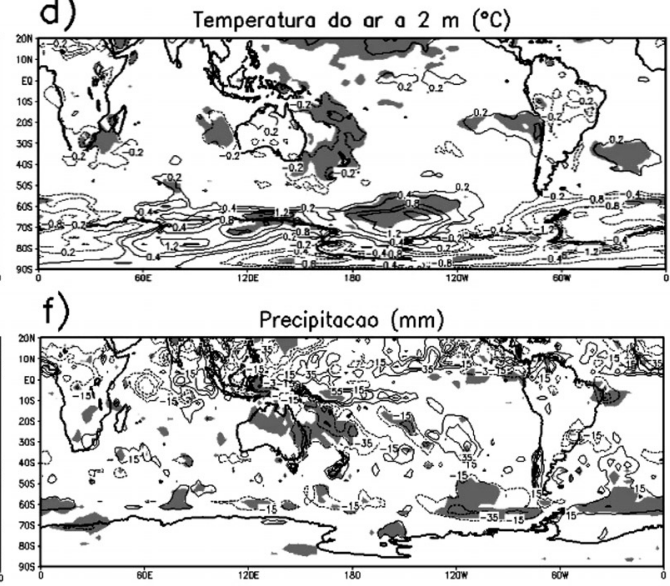

h)
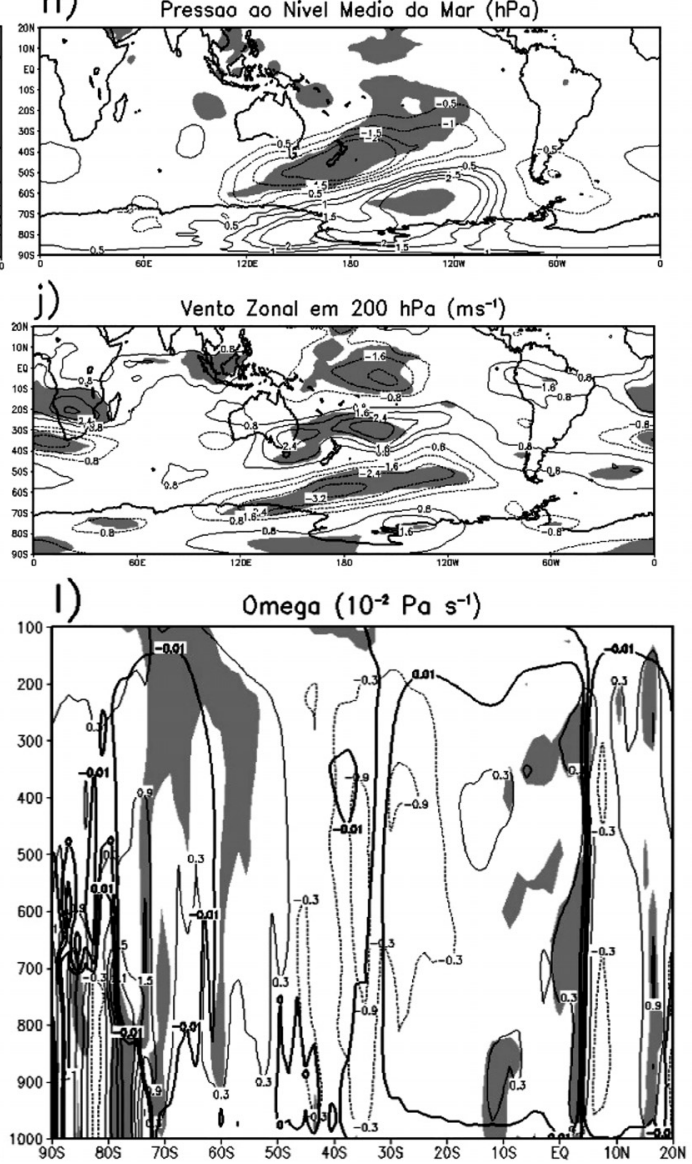

Figura 2 - (a, b) Anomalia de temperatura da superfície do mar $\left({ }^{\circ} \mathrm{C}\right),(\mathrm{c}, \mathrm{d})$ anomalia de temperatura do ar a $2 \mathrm{~m}\left({ }^{\circ} \mathrm{C}\right),(\mathrm{e}, \mathrm{f})$ anomalia de precipitação (mm), $(\mathrm{g}, \mathrm{h})$ pressão ao nível médio do mar $(\mathrm{hPa}),(\mathrm{i}, \mathrm{j})$ anomalia de vento zonal em $200 \mathrm{hPa}\left(\mathrm{ms}^{-1}\right)$ e (k, l) seção vertical da anomalia e média (linha contínua grossa) de velocidade vertical (omega, $10^{-2} \mathrm{~Pa} \mathrm{~s}^{-1}$ ) média no setor do Pacífico Sudeste durante os eventos extremos de retração (coluna da esquerda) e expansão (coluna da direita) de gelo marinho no setor do mar de Weddell. As anomalias são calculadas em relação ao período de inverno austral (JAS) entre 1979-2013. Linhas finas contínuas (pontilhadas) indicam anomalias positivas (negativas). Áreas em cinza são significativas ao nível de 10\%. O número de eventos independentes é igual a 8 e 9 , respectivamente. 


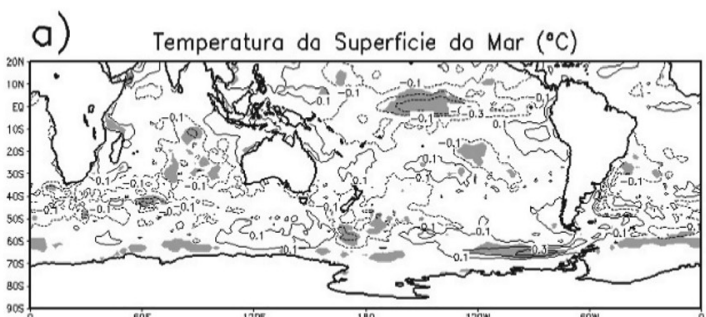

C) Temperotura do ar o $2 \mathrm{~m}\left({ }^{\circ} \mathrm{C}\right)$

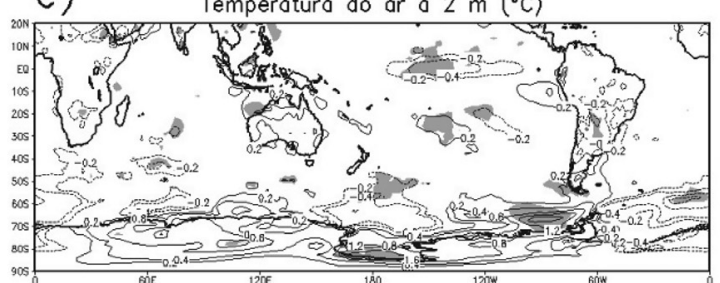

e) Precipitocio $(\mathrm{mm})$
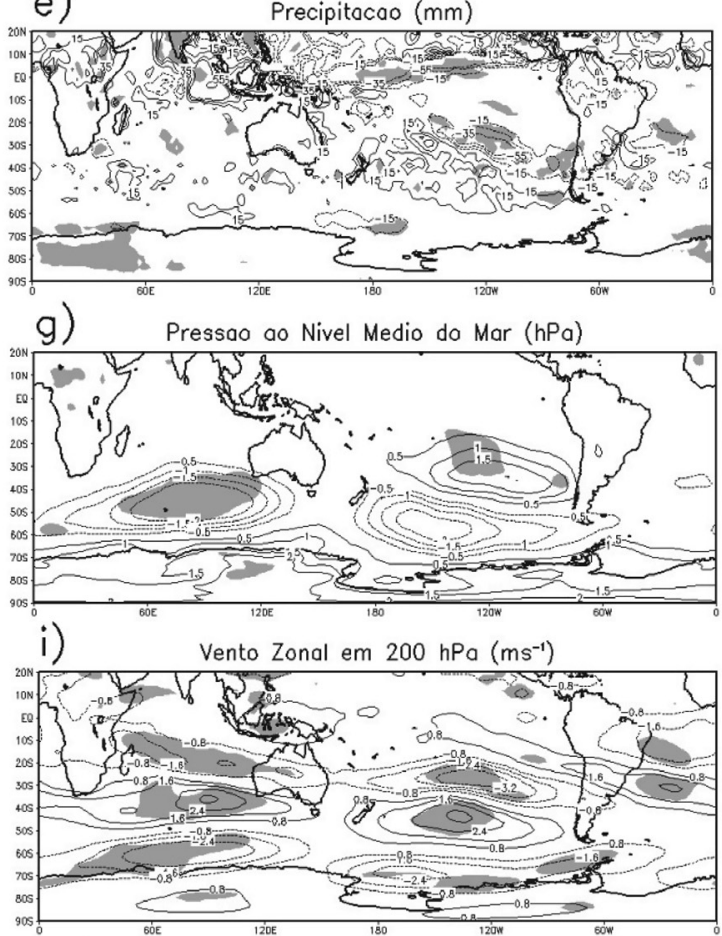

k) Omega $\left(10^{-2} \mathrm{~Pa} \mathrm{~s}^{-1}\right)$

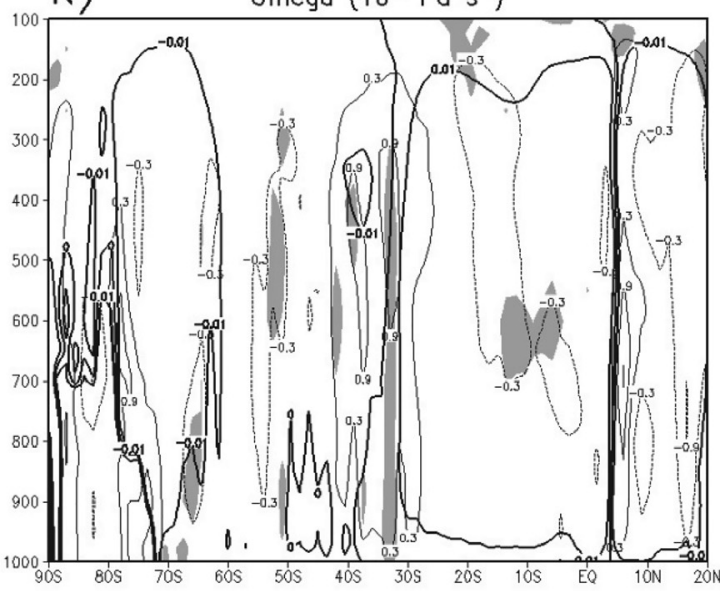

b) Temperatura da Superficie do Mar $\left({ }^{\circ} \mathrm{C}\right)$

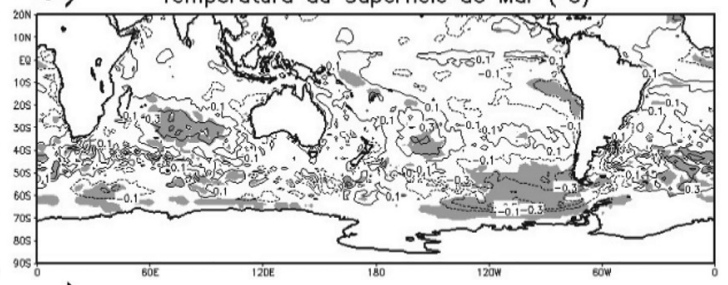

d)

Temperaturo do ar o $2 \mathrm{~m}\left({ }^{\circ} \mathrm{C}\right)$
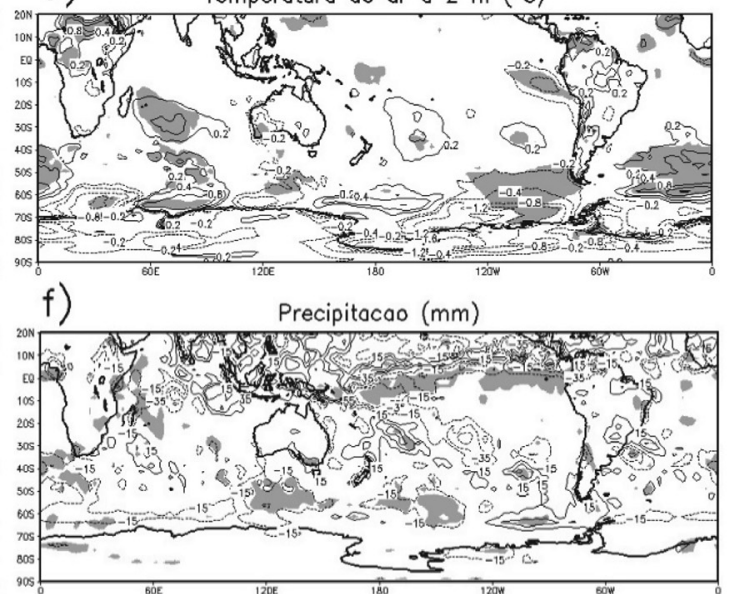

h)
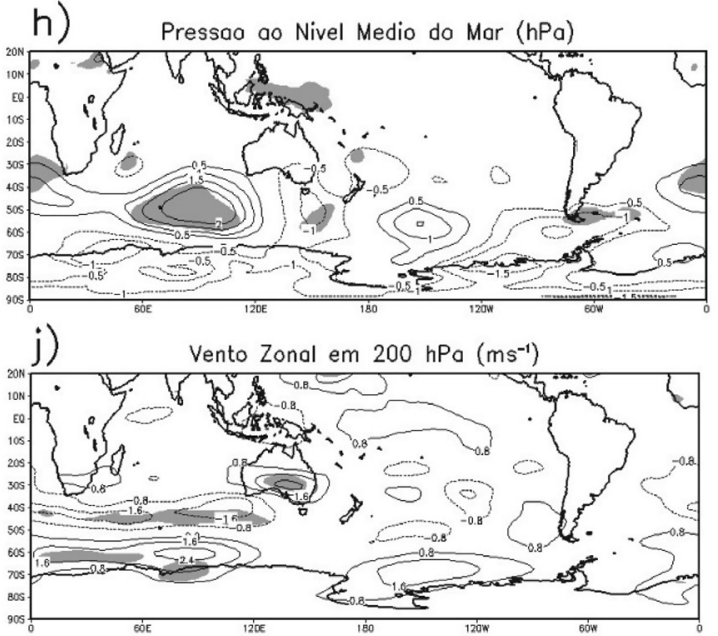

I) Omega $\left(10^{-2} \mathrm{~Pa} \mathrm{~s}^{-1}\right)$

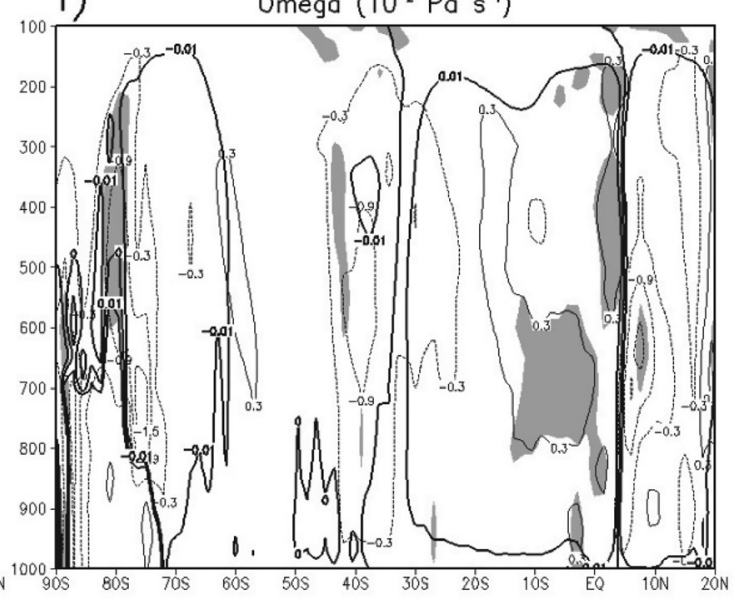

Figura 3 - Similar à Fig. 2, mas para o setor dos mares de Bellingshausen-Amundsen. O número de eventos independentes é igual a 9 e 9 , respectivamente. 


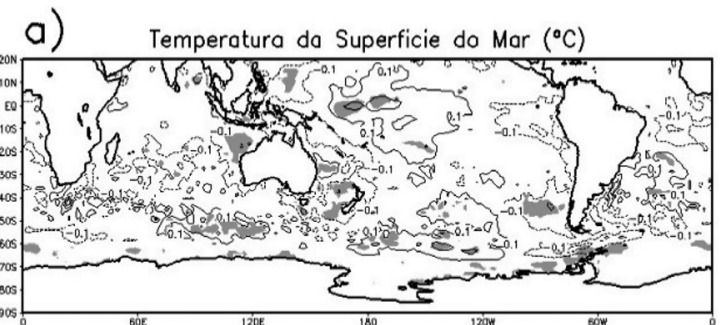

b) Temperotura do Superficie do Mar $\left({ }^{\circ} \mathrm{C}\right)$
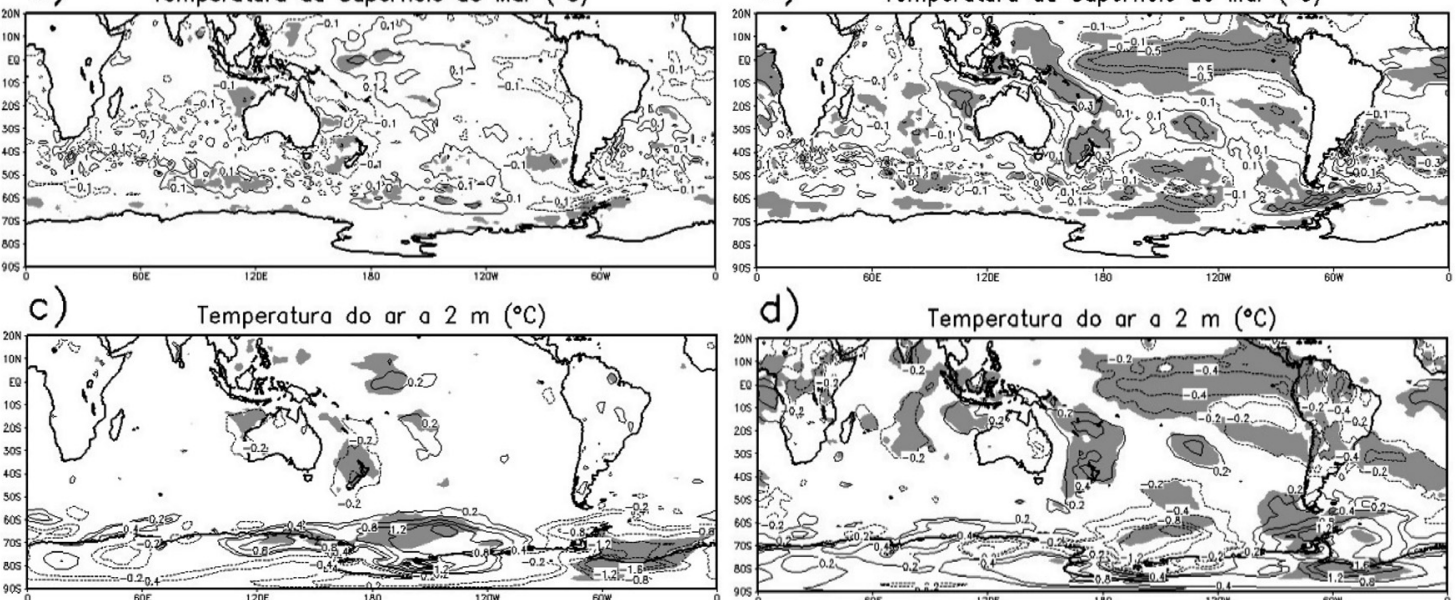

d) Temperotura do or $\circ 2 \mathrm{~m}\left({ }^{\circ} \mathrm{C}\right)$
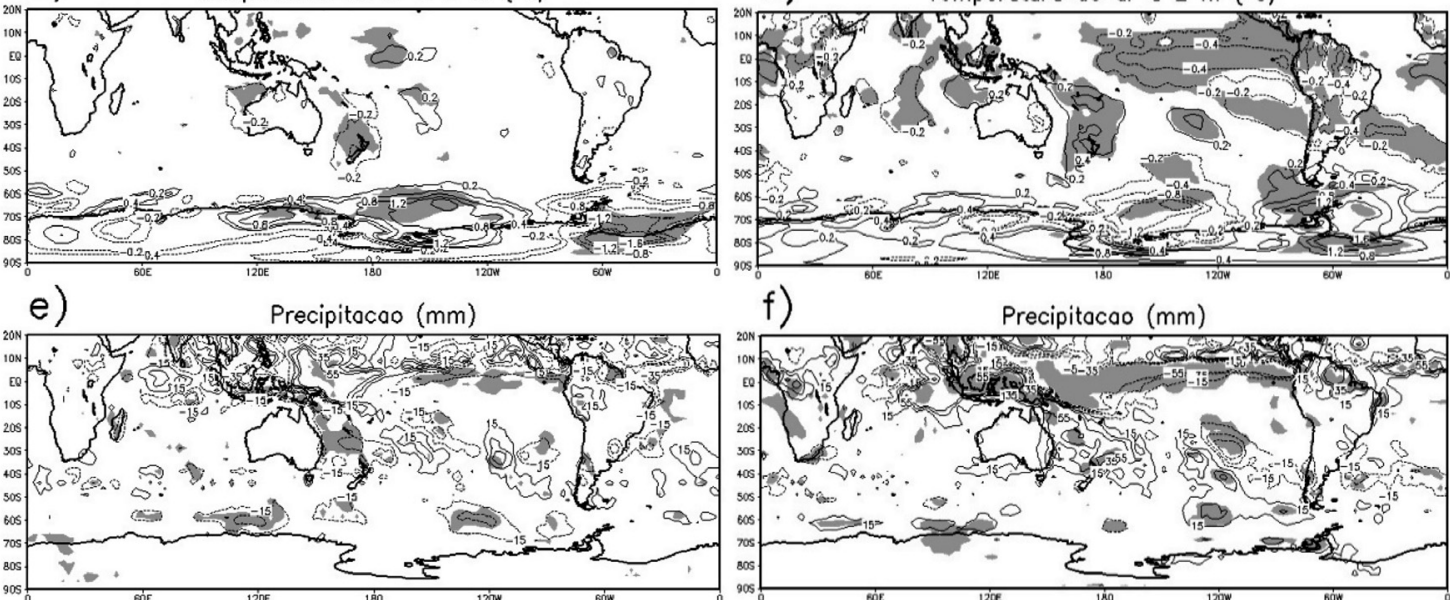

f)

Precipitocao (mm)

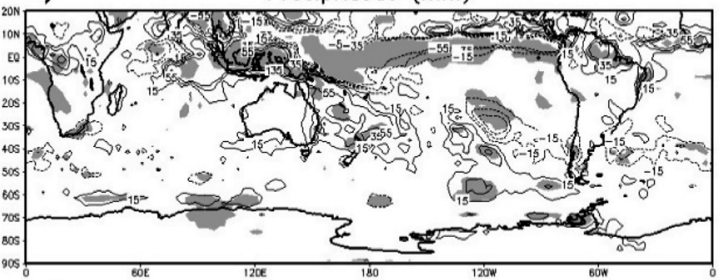

g) Pressao ao Nivel Medio do Mor $(\mathrm{hPa})$

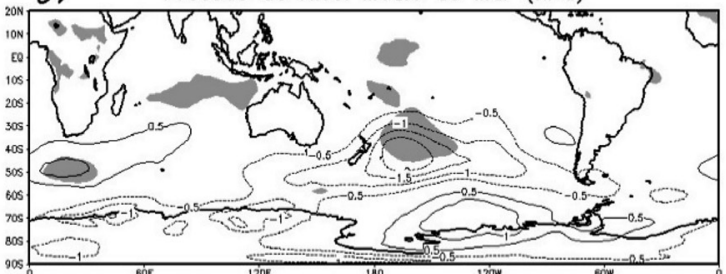

h) Pressao ao Nivel Medio do Mor (hPa)
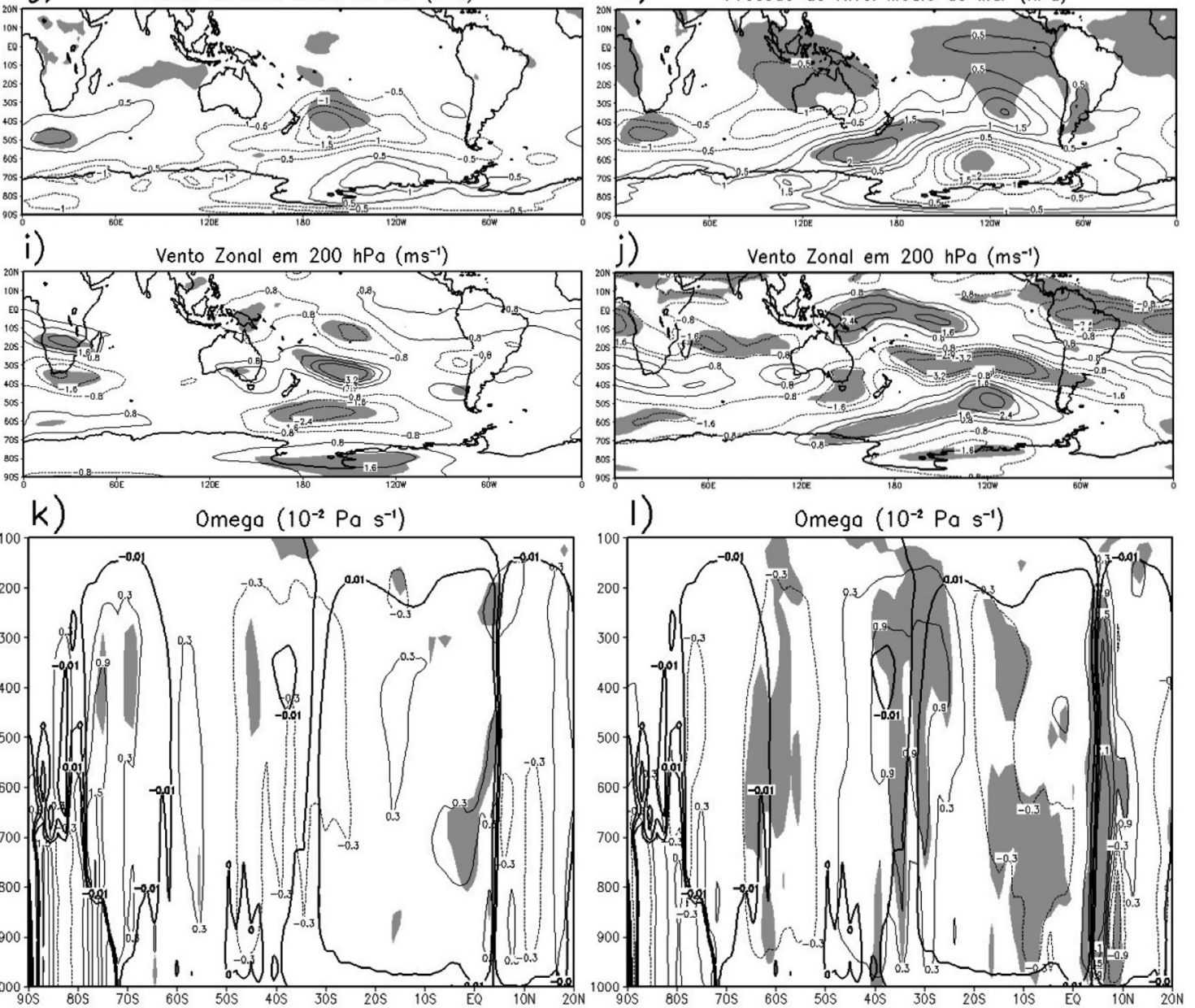

Figura 4 - Similar à Fig. 2, mas para o setor do mar de Ross. O número de eventos independentes é igual a 10 e 10, respectivamente. 

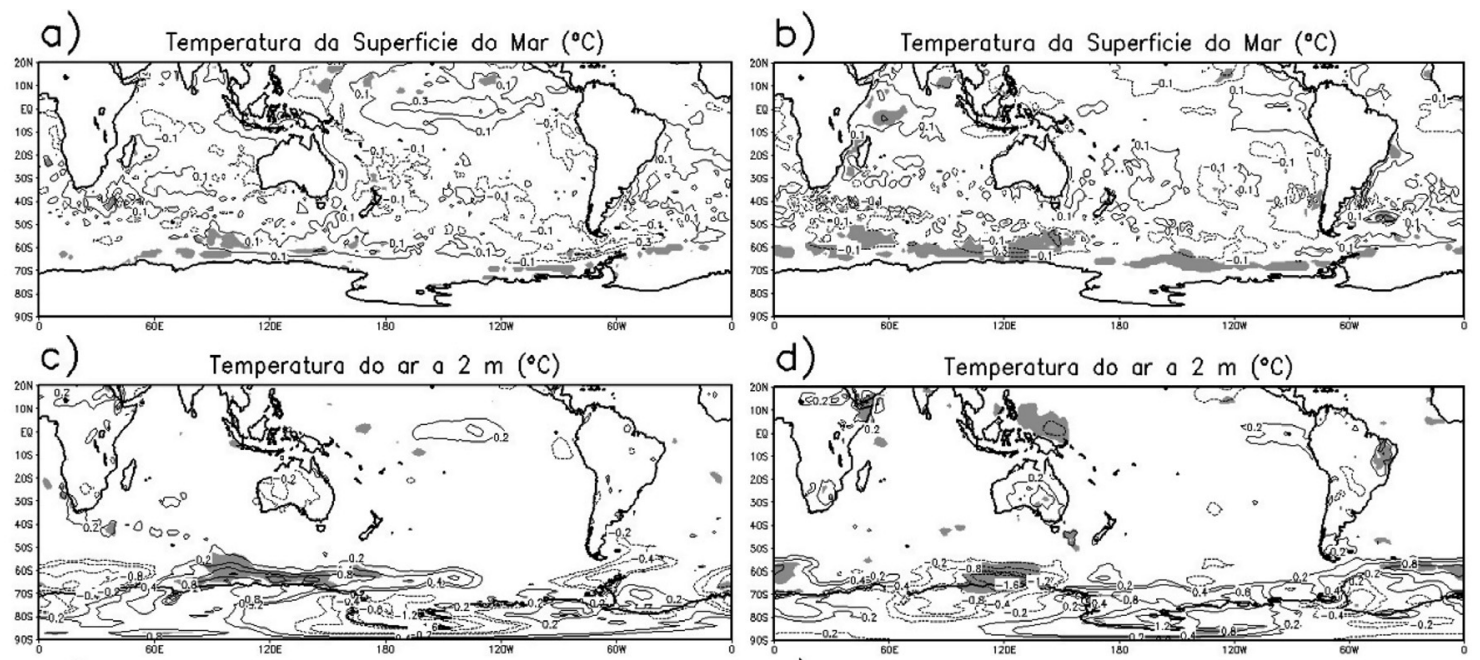

d) Temperatura do or $02 \mathrm{~m}\left({ }^{\circ} \mathrm{C}\right)$
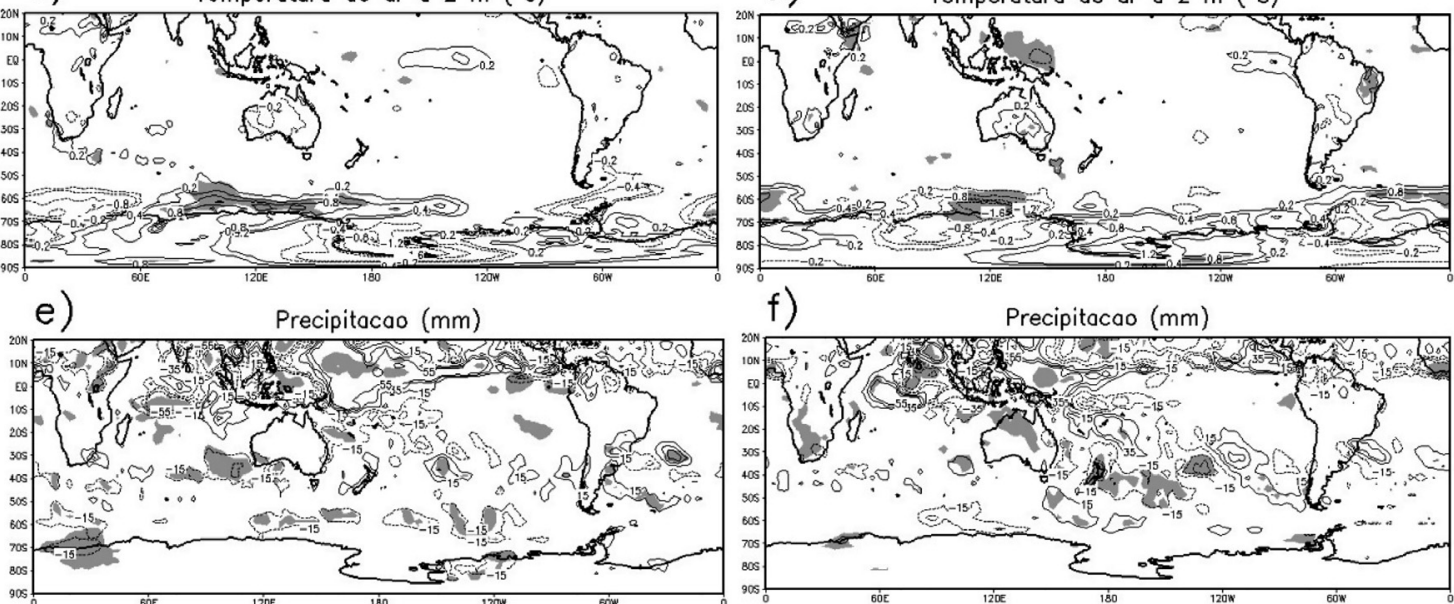

f) Precipitacao $(\mathrm{mm})$
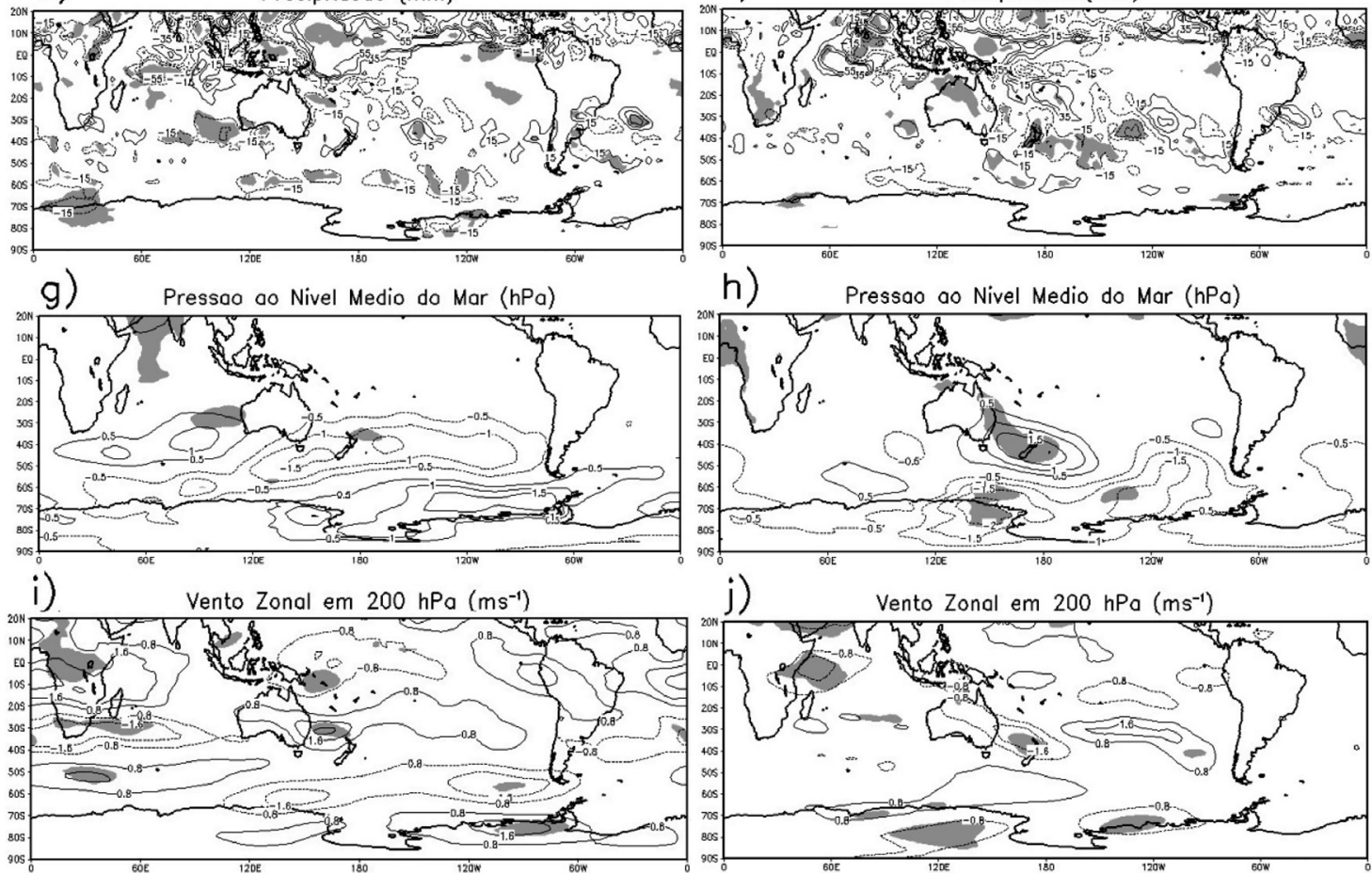

h) Pressao ao Nivel Medio do Mar (hPa)
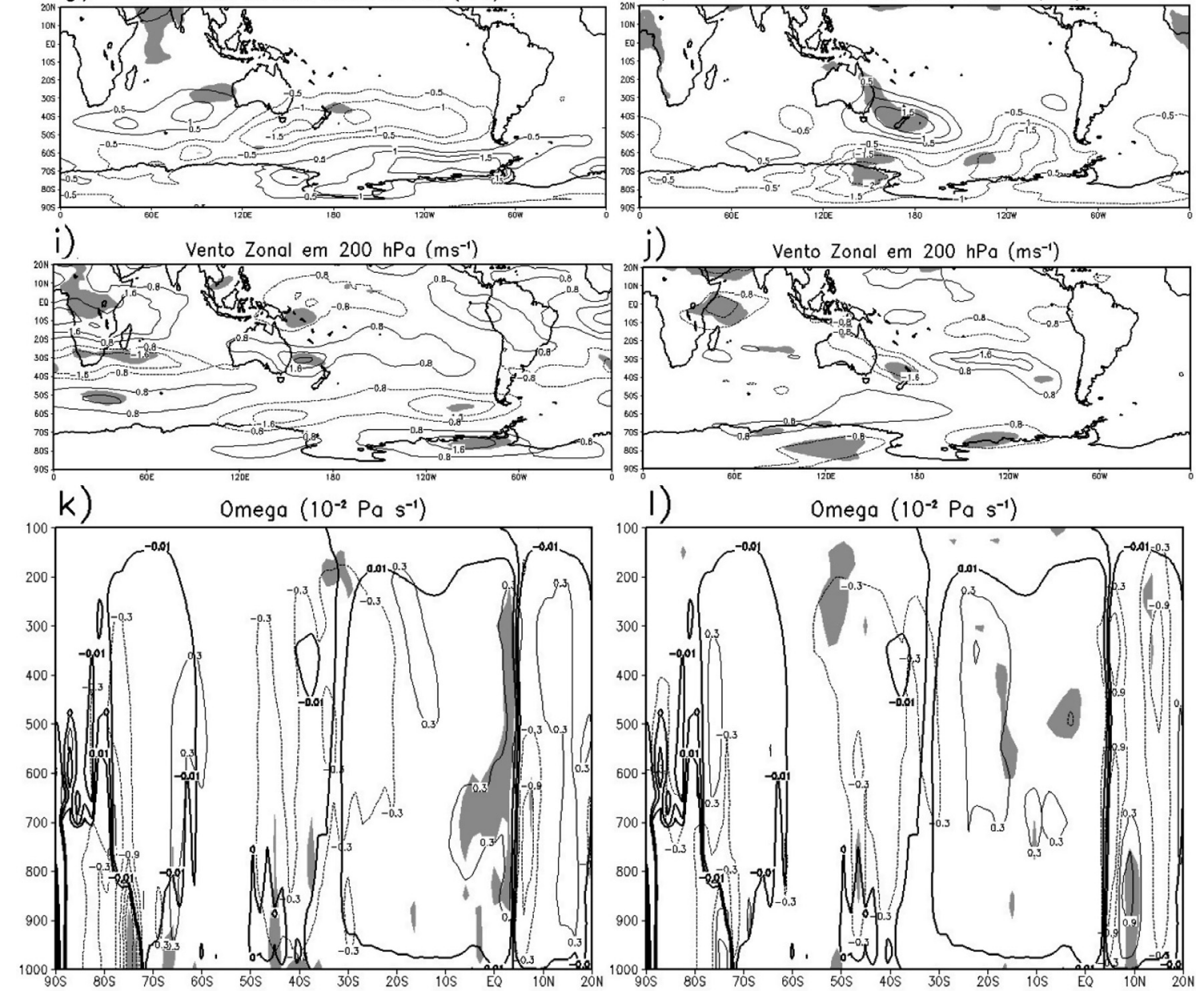

Figura 5 - Similar à Fig. 2, mas para o setor do Oceano Pacífico Oeste. O número de eventos independentes é igual a 9 e 10, respectivamente. 
peratura e pressão em superfície, o que reduz a PNMM (Fig. 3f) e possivelmente favorece uma maior atividade ciclônica na região (cf. Yuan, 2004; Song et al., 2011). Desta forma, em cerca de $45^{\circ} \mathrm{S}$ há um fortalecimento do ramo ascendente da célula de Ferrel em toda a troposfera, enquanto o ramo descendente da célula Polar enfraquece (Fig. 3j). Na região equatorial há um fortalecimento do ramo ascendente da célula de Hadley entre $5^{\circ} \mathrm{N}$ e $10^{\circ} \mathrm{N}$ nos baixos e médios níveis e do ramo descendente entre $15^{\circ} \mathrm{S} \mathrm{e}$ o Equador. Por outro lado, durante os eventos extremos de retração há um fortalecimento do ramo descendente de Hadley em toda a troposfera em torno de $35^{\circ} \mathrm{S}$ (Fig. 3i), bem como da PNMM (Fig. 3e), o que indica um fortalecimento da Alta Subtropical do Pacífico Sul. O ramo ascendente da célula de Ferrel enfraquece em torno de $40^{\circ} \mathrm{S}$, o que possivelmente indica um deslocamento para sul da célula de Ferrel. Em cerca de $50^{\circ} \mathrm{S}$ há um leve fortalecimento do ramo ascendente de Ferrel em níveis médios. Esse padrão de circulação anômalo é semelhante ao segundo modo do PSA. O PSA é o modo dominante da variabilidade climática de baixa frequência entre a região tropical do Pacífico/Indonésia e a América do Sul, sendo a segunda e terceira EOF (Empirical Orthogonal Function) de altura geopotencial em $500 \mathrm{hPa}$ (Mo e Ghil, 1987; Mo e Higgins, 1998; Mo e Paegle, 2001). O PSA é o padrão mais diretamente relacionado à variabilidade do fenômeno tropical ENOS e tem maior influência sobre o gelo marinho na escala de tempo interanual e na região do Dipolo Antártico, ou seja, nos setores da Antártica localizados no centro-leste do Pacífico Sul e Atlântico Sul (Yuan e Li, 2008).

Quando há eventos extremos de retração (expansão) de gelo marinho no setor do mar de Ross há um aquecimento (resfriamento) da TSM no Pacífico Sul [Fig. 4a (4b)]. Assim, a atmosfera adjacente aquece (resfria) [Fig. 4c (4d)], diminuindo (aumentando) os gradientes térmicos entre a borda do gelo marinho e a região de mar aberto. Os gradientes meridionais de pressão são enfraquecidos (fortalecidos), o que enfraquece (fortalece) o cinturão circumpolar de baixas pressões [Fig. 4e (4f)] e o jato polar [Fig. 4g (4h)]. Isso possivelmente favorece uma menor (maior) atividade ciclônica na região ( $c f$. Yuan, 2004; Song et al., 2011). Assim, há um enfraquecimento (fortalecimento) do ramo ascendente da célula de Ferrel em torno de $70^{\circ} \mathrm{S}\left(60^{\circ}\right.$ $\mathrm{S})$ no Pacífico Sudeste, enquanto nas latitudes menores, em torno de $45^{\circ} \mathrm{S}\left(40^{\circ} \mathrm{S}\right)$, há um fortalecimento (enfraquecimento) [Fig. 4i (4j)]. Durante os eventos extremos de expansão de gelo marinho há anomalias negativas de TSM no Pacífico Equatorial (Fig. 4a), o que resulta em redução da convecção tropical e consequente enfraquecimento do ramo ascendente da célula de Hadley entre o Equador e $10^{\circ}$ $\mathrm{N}$ em toda a troposfera e do ramo descendente entre $20^{\circ} \mathrm{S} \mathrm{e}$ o Equador (Fig. 4j). Entre $25^{\circ}$ e $40^{\circ} \mathrm{S}$ o ramo descendente é intensificado, o que poderia indicar um fortalecimento da Alta Subtropical do Pacífico Sul. O padrão de circulação anômalo durante os eventos extremos de gelo marinho no setor do mar de Ross é semelhante ao primeiro modo do PSA (Mo e Paegle, 2001).

Durante os eventos extremos de retração (expansão) de gelo marinho no setor do Oceano Pacífico Oeste há aquecimento (resfriamento) da TSM neste setor [Fig. 5a $(5 \mathrm{~b})] \mathrm{e}$, assim, da temperatura do ar próximo à superfície [Fig. 5c (5d)], enquanto no Pacífico Sudeste há resfriamento da TSM. Desta forma, em eventos extremos de expansão de gelo marinho há uma redução da PNMM no Pacífico Sudeste (Fig. 5f) e consequente fortalecimento do ramo ascendente de Ferrel em torno de $55^{\circ} \mathrm{S}$ (Fig. 5j), o que indica um fortalecimento do cinturão circumpolar de baixas pressões, favorecendo uma maior atividade ciclônica na região (cf. Yuan, 2004; Song et al., 2011). Pezza et al., (2008) observaram um aumento na densidade de ciclones em grande parte do Oceano Austral, com exceção do Atlântico Sul, durante os cinco anos com maior extensão de gelo marinho em relação aos cinco anos com menor extensão no setor do Oceano Pacífico Oeste entre 1979 e 2003. O ramo descendente da célula de Hadley é fortalecido nos níveis médios em torno de $20^{\circ} \mathrm{S}$. Por outro lado, nos eventos extremos de retração há um fortalecimento do ramo descendente de Hadley entre $10^{\circ} \mathrm{S}$ e $5^{\circ} \mathrm{N}$, enquanto há fortalecimento do ramo ascendente de Ferrel entre $40^{\circ}$ e $50^{\circ} \mathrm{S}$ em baixos níveis (Fig. 5i).

Em eventos extremos de retração (expansão) de gelo marinho no setor do Oceano Índico há predomínio de aquecimento (resfriamento) da TSM no Oceano Austral [Fig. 6a (6b)], bem como da temperatura do ar próximo à superfície [Fig. 6c (6d)], com exceção do Atlântico Sul. Desta forma, há um aumento (redução) da PNMM em torno de $60^{\circ} \mathrm{S}$ e redução (aumento) nas latitudes médias [Fig. 6e (6f)], de forma que o escoamento zonal de oeste é enfraquecido (fortalecido) [Fig. 6g (6h)]. Esse padrão anômalo é semelhante à fase negativa (positiva) da Oscilação Antártica (Antarctic Oscillation - AAO), que é o principal modo de variabilidade entre as latitudes médias e altas do Hemisfério Sul (Kidson, 1988; Kidson e Watterson, 1999; Thompson e Wallace, 2000; Renwick, 2002; Marshall, 2003). Durante a fase positiva da AAO existe resfriamento sobre o continente antártico devido ao fortalecimento do escoamento de oeste em torno de $60^{\circ} \mathrm{S}$, o qual inibe as trocas de massa entre as latitudes médias e altas (Thompson e Solomon, 2002), bem como intensifica o transporte de Ekman, aumentando a ressurgência de águas subsuperficiais frias (Gillett et al., 2006). Além disso, resfriamento adiabático também ocorre devido ao abaixamento da altura geopotencial sobre as altas latitudes austrais (Thompson e Wallace, 2000). Nas altas latitudes há um fortalecimento (enfraquecimento) do ramo descendente da célula Polar [Fig. $6 \mathrm{i}$ (6j)].

\section{Conclusões}

A variabilidade da extensão de gelo marinho antártico possui potencial de afetar a circulação atmosférica, da su- 

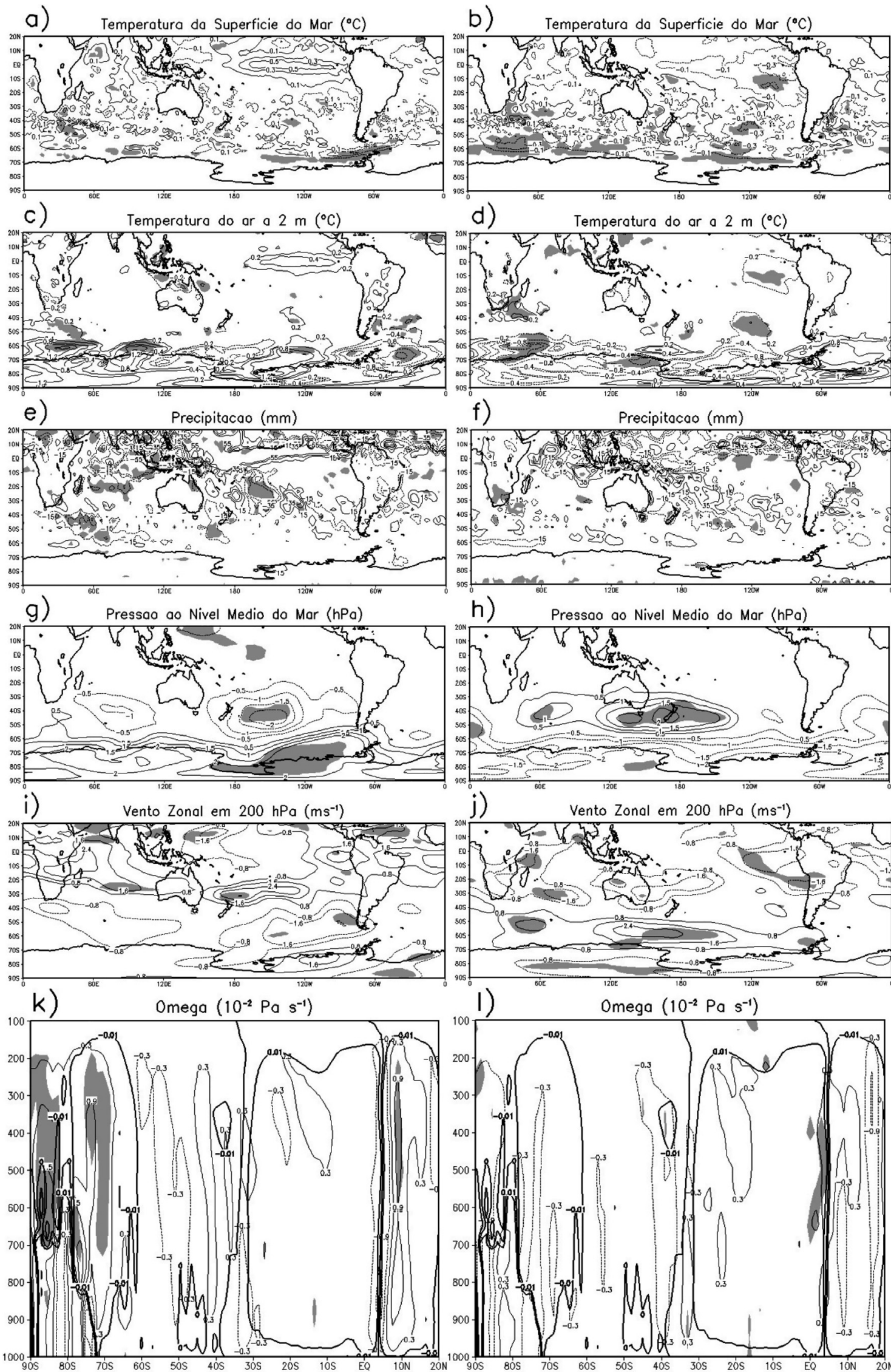

d)

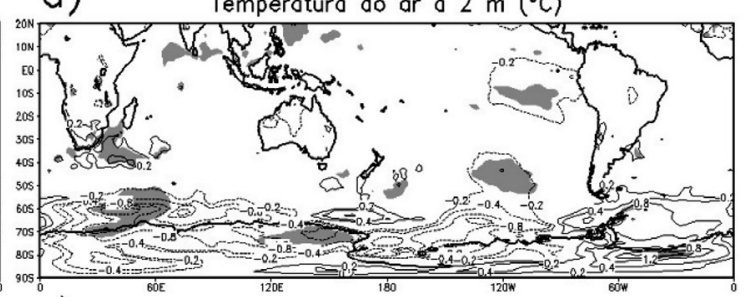

f)

Precipitacao $(\mathrm{mm})$

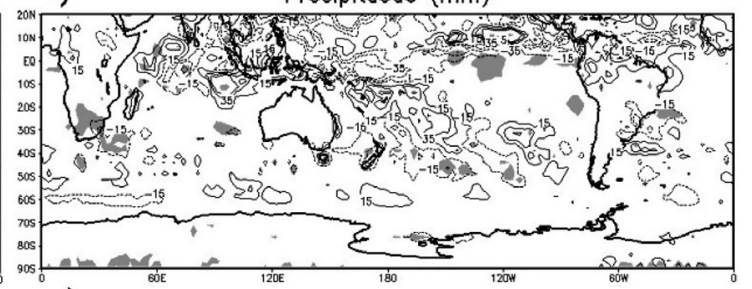

h)
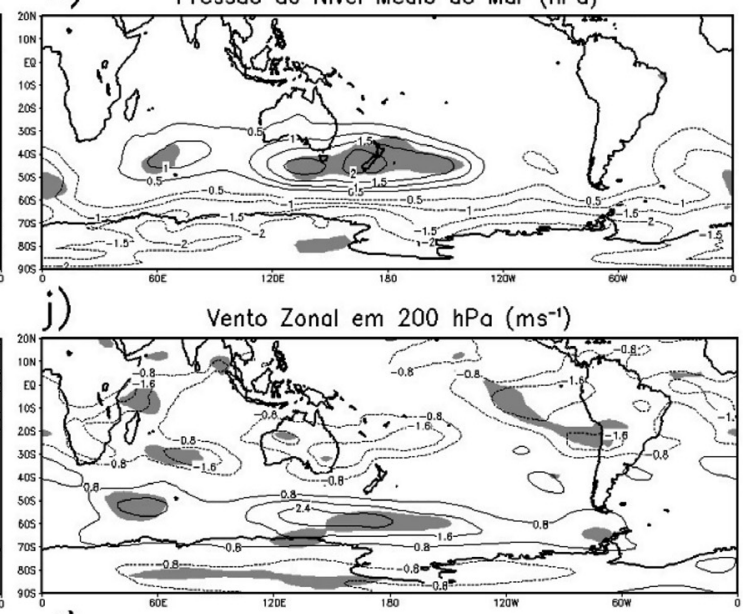

I)

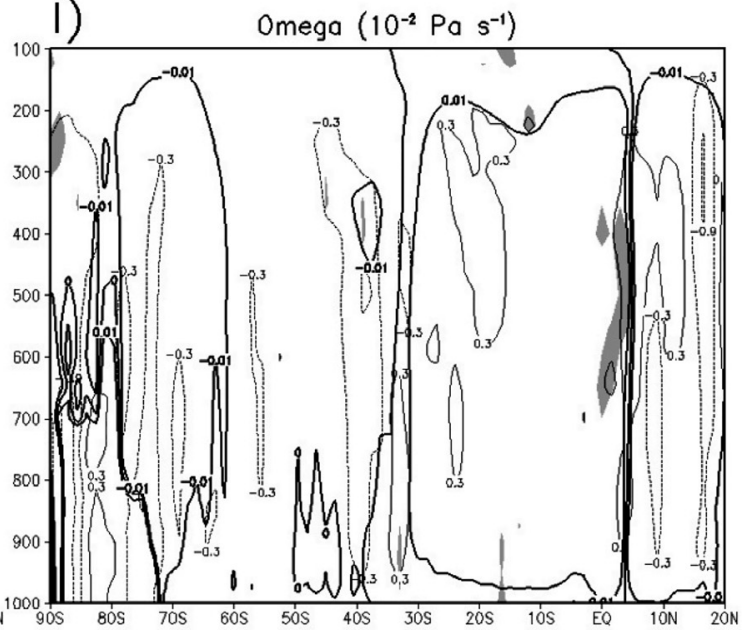

Figura 6 - Similar à Fig. 2, mas para o setor do Oceano Índico. O número de eventos independentes é igual a 8 e 9, respectivamente. 
perfície até os níveis médios da troposfera (Raphael et al., 2010; Kidston et al., 2011), pois a borda do gelo marinho antártico está localizada em uma região muito sensível, sob a Frente Polar Antártica (Raphael et al., 2010). Desta forma, com os resultados apresentados buscamos compreender qual o comportamento das células de circulação meridional no Pacífico Sudeste durante os eventos extremos de retração e expansão de gelo marinho nos diferentes setores do Hemisfério Sul. O Pacífico Sudeste é uma região chave para os estudos de variabilidade climática de alta e baixa frequência no Hemisfério Sul, sendo a localização da máxima amplitude do PSA (Mo e Ghil, 1987; Mo e Higgins, 1998; Mo e Paegle, 2001) e da maior frequência de bloqueios atmosféricos do Hemisfério Sul (Renwick, 1998; Mo e Paegle, 2001; Oliveira et al., 2013).

Nossos resultados mostram que durante os eventos extremos de expansão de gelo marinho no setor do mar de Ross durante o inverno austral há resfriamento da TSM no Pacífico Sul, o que resulta em resfriamento da atmosfera adjacente. Portanto, há um reforço dos gradientes meridionais de temperatura e pressão entre a borda do gelo marinho e a região de mar aberto, o que resulta em reforço do cinturão circumpolar de baixas pressões e do jato polar. Como consequência, existe um fortalecimento do ramo ascendente da célula de Ferrel em torno de $60^{\circ} \mathrm{S}$ no Pacífico Sudeste. Por conservação de massa, nas latitudes médias o movimento ascendente é reduzido. Assim, com a célula de Ferrel fortalecida mais ao sul quando há extremos de expansão de gelo marinho, a advecção de massas de ar para norte é limitada (Liu et al., 2002). O padrão oposto ocorre durante os eventos extremos de retração de gelo marinho no setor do mar de Ross e expansão no setor do mar de Weddell. Esse padrão anômalo é condizente com o observado por Raphael et al. (2010). Por outro lado, observamos um comportamento contrário no setor dos mares de Bellingshausen-Amundsen. Em eventos extremos de retração (expansão) de gelo marinho há um enfraquecimento (fortalecimento) do ramo ascendente de Ferrel em torno de $40^{\circ} \mathrm{S}\left(45^{\circ} \mathrm{S}\right)$, enquanto em $50^{\circ} \mathrm{S}$ há um fortalecimento somente em eventos extremos de retração.

No geral, nossos resultados mostram que a extensão da resposta anômala da circulação atmosférica e da TSM é muito maior em eventos extremos de expansão de gelo marinho. Esse resultado altamente antissimétrico sugere que os processos envolvidos na relação entre eventos extremos de gelo marinho e anomalias da circulação atmosférica e da TSM são não lineares. Estas observações são consistentes com Cunningham e Bonatti (2011).

\section{Agradecimentos}

Os autores agradecem à Fundação de Amparo à Pesquisa do Estado de São Paulo - FAPESP (processos $\mathrm{N}^{\circ}$ 2012/17370-2 e 2008/58101-9), ao CNPq e ITV (Instituto Vale de Tecnologia) por suporte financeiro.

\section{Referências}

BENGTSSON, L.; ARKIN, P.; BERRISFORD, P.; BOUGEAULT, P.; FOLLAND, C.K. et al. The need for a dynamical climate reanalysis. Bull. Am. Meteorol. Soc., v. 88, n. 4, p. 495-501, 2007.

BERRISFORD, P.; DEE, D.P.; POLI, P.; BRUGGE, R.; FIELDING, K., et al. The ERA-Interim Archive. ERA Report Series, n.1. ECMWF: Reading, UK. 2009. 23p.

CAVALIERI, D.J.; PARKINSON, C.L.; GLOERSEN, P.; COMISO, J.C.; ZWALLY, H.J. Deriving long-term time series of sea ice cover from satellite passive-microwave multisensor data sets. J. Geophys. Res., v. 104, n. C7, p. 803-814, 1999.

CAVALIERI, D.J.; PARKINSON, C.L. Antarctic sea ice variability and trends, 1979-2006. Geophys. Res. Lett., v. 113, p. 1-19, 2008.

CAVALIERI, D.; PARKINSON, C.; GLOERSEN, P.; ZWALLY, H.J. 1996, updated 1979-2007. Sea Ice Concentrations from Nimbus-7 SMMR and DMSP SSM/I Passive Microwave Data, [1989-2007]. Boulder, Colorado USA: National Snow and Ice Data Center. Digital media.

CUNNINGHAM, C.A.; BONATTI, J.P. Local and remote responses to opposite Ross Sea ice anomalies: a numerical experiment with the CPTEC/INPE AGCM. Theor. Appl. Climatol., v. 106, p. 23-44, 2011.

DEE, D.P. Bias and data assimilation. Q. J. R. Meteorol. Soc., v. 131, p. 3323-3343, 2005.

DEE, D.P.; UPPALA, S.M.; SIMMONS, A.J.; BERRISFORD, P.; POLI, P. et al. The ERA-Interim reanalysis: configuration and performance of the data assimilation system. Q. J. R. Meteorol. Soc., v. 137, p. 553-597, 2011.

GILLETT, N.P.; KELL, T.D.; JONES, P.D. Regional climate impacts of the Southern Annular Mode. Geophys. Res. Lett., v. 33, p. 1-4, 2006.

KIDSON, J.W. Interannual variations in the Southern Hemisphere circulation. J. Climate, v. 1, p. 1177-1198, 1988.

KIDSON, J.W.; WATTERSON, I.G. The structure and predictability of the "High-Latitude Mode" in the CSIRO9 General Circulation Model. J. Atmos. Sci., v. 56, p. 3859-3873, 1999.

KIDSTON, J.; TASCHETTO, A.S.; THOMPSON, D.W.J.; ENGLAND, M.H. The influence of Southern Hemisphere sea-ice extent on the latitude of the mid-latitude jet stream. Geophys. Res. Lett., v. 38, n. L15804, p. 1-5, 2011.

KING, J.C.; TURNER, J. Antarctic Meteorology and Climatology. 5.ed. Cambridge: University Press, 1997. 409p.

LIU, J.; YUAN, X.; RIND, D.; MARTINSON, D.G. Mechanism study of the ENSO and southern high latitude climate Teleconections. Geophys. Res. Lett., v. 29, n. 14, p. 24-1-24-4, 2002.

MARSHALL, G.J. Trends in the Southern Annular Mode from observations and reanalyses. J. Climate, v. 16, p. 41344143, 2003.

MENÉNDEZ, C.G.; SERAFINI, Y.V.; LE TREUT, H. The effect of sea-ice on the transient atmospheric eddies of the Southern Hemisphere. Clim. Dynam., v. 15, p. 659-671, 1999a.

MENÉNDEZ, C.G.; SERAFINI, Y.V.; LE TREUT, H. The storm tracks and the energy cycle of the Southern Hemisphere: sensitivity to sea-ice boundary conditions. Ann. Geophys. Atmos. Hydros. Space Sci., v. 17, p. 1478-1492, 1999 b. 
MO, K.C.; GHIL, M. Statistics and Dynamics of Persistent Anomalies. J. Atmos. Sci., v. 44, p. 877-902, 1987.

MO, K.C.; HIGGINS, R.W. The Pacific-South American modes and tropical convection during the Southern Hemisphere Winter. Mon. Wea. Rev., v. 126, p. 1581-1596, 1998.

MO, K.C.; PAEGLE J.N. The Pacific-South American modes and their downstream effects. Int. J. Climatol., v. 21, n. 10, p. 1211-1229, 2001.

OLIVEIRA, F.N.M.; CARVALHO, L.M.V.; AMBRIZZI, T. A new climatology for Southern Hemisphere blockings in the winter and the combined effect of ENSO and SAM phases. Int. J. Climatol., v. 34, p. 121-133, 2013.

PEZZA, A.B.; BURRANT, T.; SIMMONDS, I.; SMITH, I. Southern Hemisphere synoptic behavior in extreme phases of SAM, ENSO, sea ice extent, and southern Australia rainfall. J. Climate, v. 21, n. 21, p. 5566-5584, 2008.

RAPHAEL, M.N.; HOBBS, W.; WAINER, I. The effect of Antarctic sea ice on the Southern Hemisphere atmosphere during the southern summer. Clim. Dynam., v. 36, p. 1403 1417,2010

RENWICK, J.A. ENSO-Related Variability in the Frequency of South Pacific Blocking. Mon. Weather Rev., v. 126, p. 3117-3126, 1998.

RENWICK, J.A. Southern Hemisphere circulation and relations with sea ice and sea surface temperature. J. Climate, v. 15, p. 3058-3068, 2002.

SIMMONDS, I.; BUDD, W.F. Sensitivity of the southern hemisphere circulation to leads in the Antarctic pack ice. Quart. J. Roy. Meteor. Soc., v. 117, p. 1003-1024, 1991.

SIMMONDS, I.; WU, X.R. Cyclone behavior response to changes in winter Southern Hemisphere sea-ice concentration. Q. J. Roy Meteor. Soc., v. 119, n. 513, p. 1121-1148, 1993.

SIMMONS, A.J.; UPPALA, S.; DEE, D.; KOBAYASHI, S. ERA-Interim: New ECMWF reanalysis products from 1989 onwards. ECMWF Newsletter, v. 110, p. 2-35, 2007.

SIMMONS, A.J.; UPPALA, S.M.; DEE, D.P. Update on ERAInterim. ECMWF Newsletter, v. 111, n. 5, 2007.
SIMÕES, J.C. Glossário da língua portuguesa da neve, do gelo e termos correlatos. Pesquisa Antártica Brasileira, v. 4, p. 119-154, 2004.

SONG, H.-J.; CHOI, E.; LIM, G.-H.; KIM, Y.H.; KUG, J.-S. et al. The central Pacific as the export region of the El Niño Southern Oscillation sea surface temperature anomaly to Antarctic sea ice. J. Geophys. Res., v. 116, n. D21113, p. 1-12, 2011.

TALJAARD, J.J. Synoptic meteorology of the Southern Hemisphere. Meteorology of the Southern Hemisphere, Meteorology. Monography, n.35, American Meteorological Society, p. 139-211, 1972.

TANG, Q.; ZHANG, X.; FRANCIS, J.A. Extreme summer weather in northern mid-latitudes linked to a vanishing cryosphere. Nature Climate Change, v. 4, p. 45-50, 2014.

THOMAS, D.N.; DIECKMANN, G.S. (Ed.) Sea Ice. 2.ed. Wiley, 2010. 621p.

THOMPSON, D.W.J.; WALLACE, J.M. Annular modes in the extratropical circulation. Part I: Month-to-month variability. J. Climate, v. 13, p. 1000-1016, 2000.

UPPALA, S.; DEE, D.; KOBAYASHI, S.; BERRISFORD, P.; SIMMONS, A. Towards a climate data assimilation system: status update of ERA-interim. ECMWF Newsletter, v. 115, p. $12-18,2008$.

WADHAMS, P. Ice in the ocean. Amsterdam: Gordon and Breach Science Publishers, 2000. 351p.

YUAN, X.; LI, C. Climate modes in southern high latitudes and their impacts on Antarctic sea ice. J. Geophys. Res., v. 113, n. C06S91, p. 1-13, 2008.

YUAN, X.J. ENSO-related impacts on Antarctic sea ice: a synthesis of phenomenon and mechanisms. Antarct. Sci., v. 16, n. 4, p. 415-425, 2004.

ZWALLY, H.J.; COMISO, J.C.; PARKINSON, C.L.; CAVALIERI, D.J.; GLOERSEN, P. Variability of Antarctic sea ice 1979-1998. Geophys. Res. Lett., v. 107, n. C5, p. 1-9, 2002.

All the contents of this journal, except where otherwise noted, is licensed under a Creative Commons Attribution License CC-BY. 